\title{
Royal Society Mond Laboratory
}

1 HE new Royal Society Mond Laboratory (Fig. I) which has been presented to the University of Cambridge by the Royal Society was formally opened on February 3 by the Chancellor of the University, Mr. Stanley Baldwin.

The ceremony was preceded by an official luncheon in Corpus Christi College, given by the Vice-Chancellor, Mr. W. Spens, who welcomed a large gathering representative of the Royal Society, the Department of Scientific and Industrial Research and most of the schools of physical science in Great Britain. After the luncheon, a meeting was held in the Arts School when the Cavendish Professor, Lord Rutherford, explained the purpose of the laboratory and gave an account of the early stages of the work of Prof. P. Kapitza, referring in particular to the great difficulties at the outset, when for a time it seemed almost impossible to construct coils which would not be disrupted by the large electromagnetic stresses developed during the experiments.

Sir Frederick Gowland Hopkins, president of the Royal Society, then formally presented the laboratory to the University. He referred to the connexion which has always existed between the Royal Society and the University, a connexion which has been particularly helped by the sequence of Cavendish professors who have also been presidents of the Royal Society. It was his privilege to convey this gift from an ancient but progressive scientific society to a still more ancient but no less progressive university.

Sir Robert Mond then gave a short address and spoke of the great interest his father, Dr. Ludwig Mond, had always shown in scientific research, an interest which was largely responsible for enabling Dewar's pioneer researches in low temperatures to be carried out and is now bearing further fruit in this gift, which the Royal Society has been able to make from the accumulated interest of the Ludwig Mond bequest. The Chancellor, in accepting the gift on behalf of the University, gave a brief account of the history of the work which has led to the construction of the Laboratory. After several years of preliminary experiments in the Cavendish Laboratory, Dr. Kapitza was able in 1925 to develop a method of producing magnetic fields of the order of 300,000 gauss by passing the heavy initial current from a short circuited alternator through a small coil. To obtain the large currents of the order of 15,000 amperes necessary for the work, a special alternator was required and its purchase was made possible by generous grants from the Department of Scientific and Industrial Research, which was farsighted enough to see the importance of the work and to support it during its infancy. The Department later provided the grant which enabled a liquid hydrogen plant to be constructed and thereby enabled cryogenic work to be taken up again in England after an interval of many years since Dewar's experiments.
The Chancellor reminded his audience that the greatness of a country in the eyes of the world and of history will be measured not so much by the size of its armaments or of its industries as by its permanent contributions to art, literature and science. Modern industry is becoming more and more depend. ent on the application of discoveries in pure science, and successful industrial rezearch is ultimately dependent on the vigorous prosecution of research in pure science. Whilst as a statesman he would accept no responsibility for the social effects of any work which might come from the Laboratory, as Chancellor he welcomed the gift for the great addition which it makes to the facilities available for experimental physics in the University.

The new laboratory, designed by Mr. H. C. Hughes, stands in the courtyard of the Cavendish Laboratory.

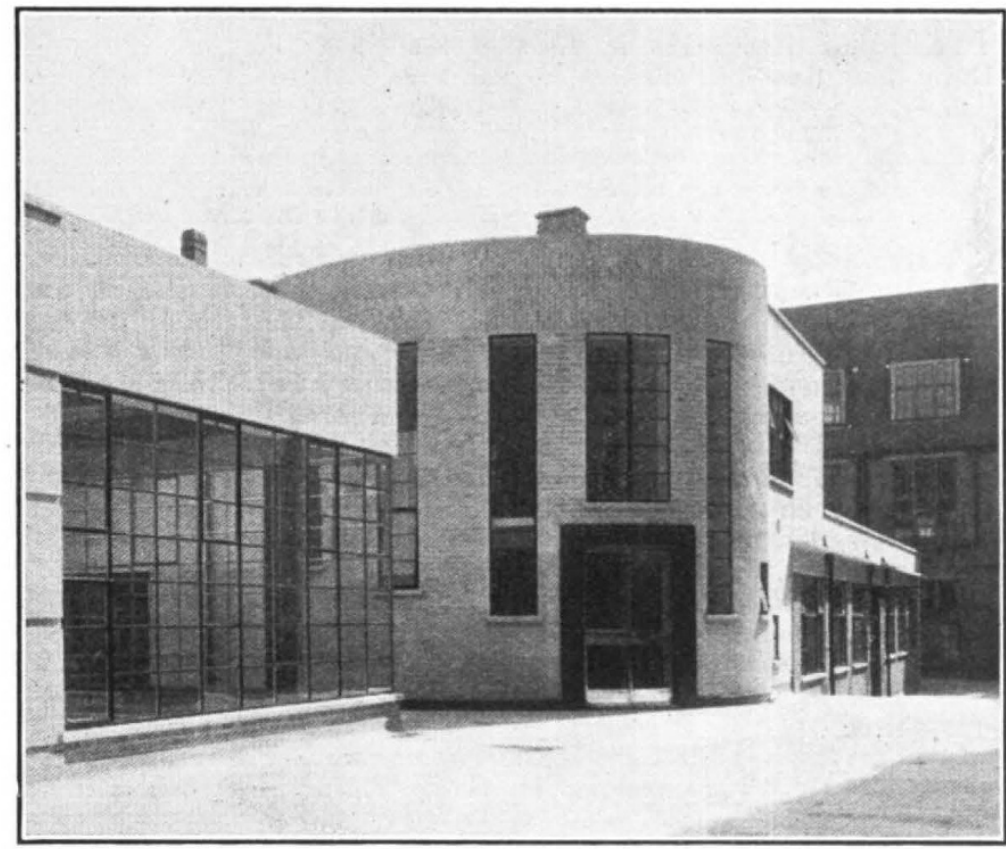

Frg. 1. Entrance to Royal Society Mond Laboratory

It has been fortunate indeed that soon after the gift of the Royal Society had been accepted, it became possible for the University to build new lecture rooms for the Department of Engineering, and so to clear away from the Cavendish site the old engineering workshops in which the School of Engineering in Cambridge was born, thereby enabling the site to be allotted to the new Laboratory. This close proximity of the Laboratory to its parent body, the Cavendish Laboratory, cannot fail to facilitate and invigorate the work of the Laboratory, since its work is, and must continue to be, mainly physical, whilst the provision of cryogenic facilities may well exert a marked influence on the future work of the Cavendish Laboratory.

Surrounded on all sides by high buildings, the Laboratory has been designed for the most part as a single storey block with a group of first floor rooms for offices at one end. The basic idea of the plan has been to separate and isolate, so far as possible, 
the research rooms from the heavy machinery which is necessary to the work of the Laboratory. The central hall shown in the plan (Fig. 2) is devoted to the main experimental apparatus of the Laboratory -the large generator which produces the very intense currents and its auxiliary apparatus. Near the generator in adjacent rooms are arranged the machine room, workshop and liquid air room. In these rooms great care has been taken to reduce the noise produced by the machinery at its source by the free use of asbestos sound absorbent; special precautions have been taken to prevent the transmission of noise through doors, and in addition, the steel frame of the building has been erected in two separate sections so that there can be no direct transmission of vibrations from the machine end to the research end of the Laboratory. The roofs of the two sections overlap and only lead aprons, a mortar joint filling and two insulating pads join the two sections. The result of these precautions has been very satisfactory, the noise of the machines and

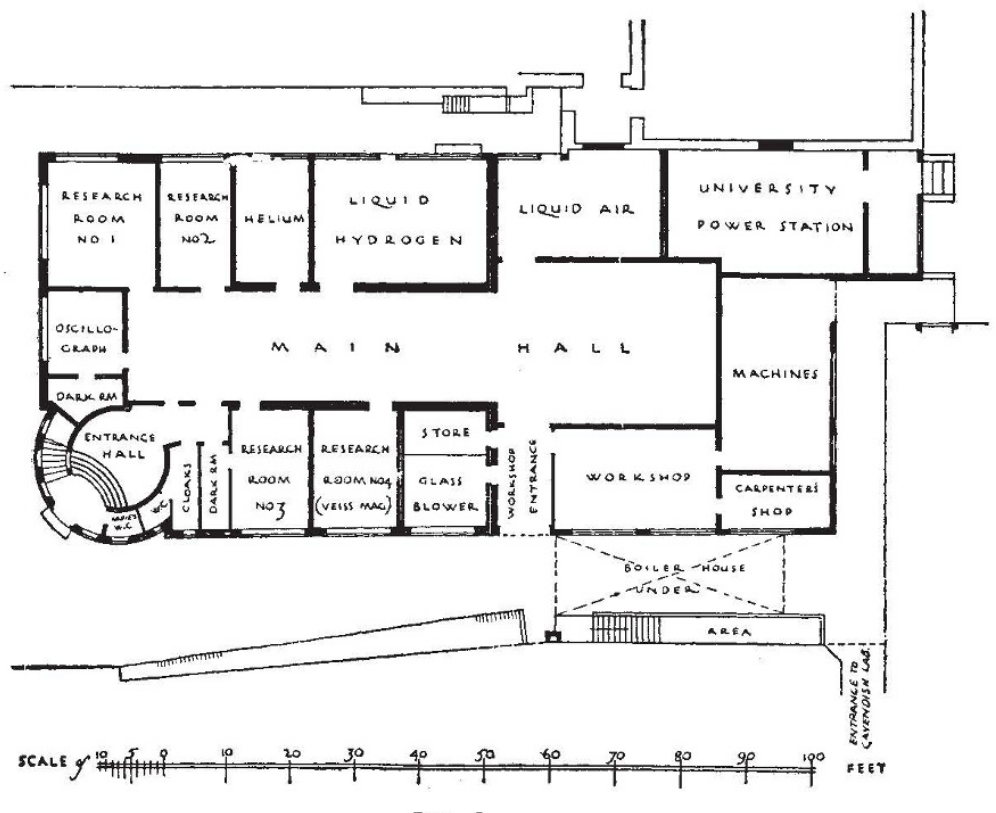

FIG. 2

liquid air plant being practically inaudible in the rest of the laboratory.

The liquid hydrogen plant already described in Nature $(129,224$, Feb. 13, 1932) has been removed to the new Laboratory, the only change made being in the system of gas storage. In place of cumbersome oil-filled gas holders which are usual for this work, a very small gas holder is used having a capacity of about 1 cubic metre, the main volume of the gas being stored at 10 atmospheres pressure in hollow steel forgings, automatic pumping plant being installed to convey the gas from the storage cylinder to the gas holder as required. In this way it is hoped to minimise the diffusion of air impurities from the oil of the gas holders into the hydrogen, one of the most common sources of trouble in liquefaction work. A further advantage lies in the great reduction of space effected, and as a result it has been possible to house both a hydrogen and helium liquefaction plant in a room about $25 \mathrm{ft} . \times 18 \mathrm{ft}$. The compressors and storage system for the helium liquefaction are installed, and it is hoped to construct the liquefier within the next few months.

The six research rooms of the Laboratory open out of the main hall at the north end. Each research room has large plate glass windows with adequate dark blind arrangements; the walls are plain distempered brick with vertical wooden strips to provide fixing accommodation for apparatus ; the rooms are heated by panel radiators fixed on the ceiling to economise floor space. An even temperature is ensured in all the research rooms, first by fitting thermostatically controlled valves to all radiators, and secondly by having an oil-fired boiler with thermostatic control of the water temperature.

In each room a concrete galvanometer foundation goes down to a depth of $10 \mathrm{ft}$. and heavy section earthing rods should ensure that independence of extraneous electrical disturbances which is so essential for magnetic researches. A cross-connexion switchboard in the main hall enables any one of five different machines to be connected to and controlled from any desired room ; at the same time each room has available a separate switchboard on which are a 220 volt battery, four terminals which can be connected to any desired cells in a 110 volt battery, a three wire automatically regulated $110 / 220$ volt D.C. supply, a four wire 3-phase A.C. supply and a galvanometer lamp supply. From the switchboard an overhead grid allows the supply to be conveyed neatly to any table in the room. Selfstarting synchronous clocks have been installed in each research room in place of the half minute impulse clocks, to eliminate the magnetic disturbances which are apt to be introduced by the impulse type. All the synchronous clocks are fed from a central point near a master clock which is fitted with both synchronous and impulse dials, and a frequency change arrangement enables all the clocks to be actuated from this point should a failure of supply lead to stoppage. The master clock is also used to provide seconds impulses to any room if required.

Every advantage has been taken of the flexibility allowed by modern building materials to meet the special requirements of the Laboratory at the least possible expense. As a result, the average cost has been less than 1s. $3 d$. per ft. cube, of which 10 per cent was for special foundations. The main decorative features of the interior are the attractive modern furniture designed by the architect, Mr. H. C. Hughes, and the gay colourings of the pipes conveying the different services. The only decorative feature of the exterior is the crocodile rampant excised in the white bricks by Mr. Eric Hill. Of the many explanations of the significance of this carving, we may record one--to the sculptor at least it signifies "Science Devouring Culture". The exterior of the building has been faced with white Leighton Buzzard bricks; these together with the large plate glass windows and circular entrance give the building a modernist character, whilst at the same time its simplicity should enable it to be a harmonious neighbour to its very mixed surroundings. 